\title{
Empirical study on the role of Procedural Justice in Performance appraisal on Turnover Intentions Mediating role of Organizational Politics
}

\author{
Zain Dar, Naintara Sarfraz Raja \\ Foundation University Rawalpindi Campus (FURC) New Lalazar, Rawalpindi, Cantt. Pakistan. \\ Assistant Professor Department of Business and Economics Foundation University Rawalpindi Campus \\ (FURC) New Lalazar, Rawalpindi, Cantt. Pakistan.
}

\begin{abstract}
Purpose: The purpose of the study to examine the relationship of Procedural Justice in Performance appraisal on Turnover Intentions. Fair performance appraisal of the employees.

Design/Methodology/Approach: It analyzes a combination of $\mathrm{Hr}$ practices and its application on the Management issues to enhance the productivity and overcome the turnover ratio.

The framework particularly focuses on the application and usefulness of Organization Development (OD) by identifying different causes of turnover.

Findings: The model sufficiently addresses the results accepted the entire hypothesis and there is significant relationship between variables.

Originality/value: The existing studies contribute to establish performance models and the introduction of their concepts into the management issues. Focusing on the crucial variable Politics as mediator in the study.
\end{abstract}

\section{Introduction:}

Performance appraisal is major component of human resource and is remained a very versatile topic for organizational Scholars (Dulebon and ferris, 1999). Performance appraisal is a managerial tool favors the managers to evaluate the employees performance and rate that performance accurately. This accuracy refers to the lethal justice and to the equality in the process used in making desired allocation decision (Greenberg, 1987). The scope of the study is to examine how procedural justice in performance appraisal will affect the turnover intention of employee and the mediating role of organizational politics between these two variables. Researchers have been suggested to understand and learn more about on organizational justice perception and turn over intentions.

Turnover intention is an important issue in an organization (Abbas \& Hollman,2006 : Price; Staw 2000) Inclined in the Graph of employee turnover can be costly for employers and firm productivity and performance and cause negative impacts (Glebback \& Bax,2004). It exists in every organization despite of its size, market share and the significance of the industry. Turnover intentions leading to actual turnover is one of the most significant cause of lower level of productivity and employees self esteem both in public and private sectors in all the industries including manufacturing, It and service industry (Walter , 2009).

Organizational politics is one of the major reasons to increase the turnover intention of employees. Politics can be defined as an influence process that is exercised with in work settings. It is a broad and influential tool that can affect the working of the organization. More specifically we can explain organizational politics as it is emphasized to concept that is designed to gain and maximize short term and long term self interests over the concerns of others. (Ferris, Russ \& Fandt, 1989).

June.M.L.Poon (2012) examined the mediation-moderation framework in which he use distributive justice, procedural justice, effective commitment and turnover intention and this paper is published in journal of applied psychology. In his future research direction he suggested to check procedural justice and turnover intention relationship with other variables. Secondly the data will be gathered from the organizations of Pakistan. And Pakistani culture is much different from the western culture. In Pakistan organizations are more influenced by the political factors and performance appraisal procedures are affected by the political influences. The study main feature is to explore how organizational politics has a mediating role among procedural justice in performance appraisal and turnover intentions. Study focuses to examine the political influence on performance appraisal and how it contributes to increase the turnover intention of employees. Employees who feel that their organizations are providing them fair practices and procedures will be more motivated and loyal with the organization. 


\section{The objectives of the study}

- To find the relationship between procedural justice in performance appraisal, Organizational politics and Turnover intentions.

- To examine how much organizational politics affect the role of turnover intention.

- How fairness in performance appraisal affect employees outcome and force them to turnover.

\section{Literature Review:}

Procedural justice was introduced by Thibaut et al. (1974) given regards on fairness judgments to the procedural effects. The concept developed a legal setting of procedural justice given by Thibaut \& Walker (1975), it deals to control the dispute resolution primarily with the effects of process. According to the research of organizational studies, they found that organizational behavior was affected by procedural justice and it played a very important role such as organizational commitment.

The performance appraisal system of an organization allocate the rewards for their employees and give a fair perception of justice about their organization, departments, supervisors, managers and their jobs as well. They give an advice for development of their organization to better obtain their perspectives.

The concept of justice deals with the importance placed on making "fair" employee selection decisions (Arvey, 1979). What we know about justice in organizations concerns what is referred to as distributive justice (Homans, 1961) ; that is, the derived in which organizational resources are distributed among personnel (Freedman \&Montanari ,1980), and on employees reactions to

The fairness in procedural justice pertains to used in the outcomes which was determined whereas the fairness of procedural justice only concerned with the outcomes themselves. The procedural factor is a combination of almost five variables whereas the distributive factor is a combination of two variables. Folger \& Konovsky (1989) distributive justice measures to predict a more and unique satisfaction of variance with the pay.

Eventually suggested that the functionality is dependent on the contradictory needs of the appraisals which are political elements and normally they exist in every organization for example personal biases, manipulation and interruptions. Even though the contradictory demands also exists whereas there is cooperation, friendly behavior and trust in the organization.

There are many of unexpected consequences which are not relevant to the perception of justice phenomenon. The perception of injustice provides a suggestion to many of the organizational and personnel level outcomes to have in a relationship like trust is the only factor which creates an organizational justice and play an important role to influence on the organization and their functioning as well, it provides positive relation to personnel turnover and negative relationship with job satisfaction and pay.

Organizational politics becomes known in a field of understanding the managerial process and growing the values in the last decade. According to the research there are varieties of studies which have been examined that the different aspects of political behavior have not done the full variety to cover such behavior which may yield in the workplace.

Researchers and theoreticians have worked on the aspects of perceptions of institutional politics and political behavior that there is no clear difference between these two phenomenons. Whereas there is some implicit, if not explicit, assumption that the two constructs are related, the present work views political behavior and perceptions of politics as distinct and separate constructs .

Organizational turnover has been an innermost research topic for almost 90 years (Cotton and Tuttle, 1986; Tse and Lam, 2008), and number of the study show's result that insevere negative penalty for the organization (Abbasi and Hollman, 2000; Watrousetal. 2006).

\section{Hypothesis:}

\section{(Hypothesis H1-H10)}

Procedural Justice in performance Appraisal has a positive relation with Organizational Politics

Procedural Justice in performance Appraisal has a Negative relation with Organizational Politics

\section{(Hypothesis H2-H2o)}

Procedural Justice in performance Appraisal has positive relation with Turnover Intention of employees Procedural Justice in performance Appraisal has Negative relation with Turnover Intention of employees

\section{(Hypothesis H3-H3o)}

Organizational Politics has positive relation with Turnover Intentions

Organizational Politics has negative relation with Turnover Intentions

\section{Hypothesis (H4-H4o)}

Organizational politics will mediate the relationship between Fair justice in performance appraisal system and organizational politics. 
Organizational politics will not have mediating relationship between fairness in performance appraisal system and organizational politics.

\section{Methodology:}

Since the study is to be conducted to check the mediating role of organizational politics between procedural justice in performance appraisal and turnover intentions. The population selected from the service sector of Pakistan. In this research we used quantitative method and take a broad view and checked the reliability of a data in which all the participants selected randomly from the population of study. Simple random sampling is used so that all the participants have an equal chance of being selected.

\begin{tabular}{|c|c|c|}
\hline $\begin{array}{l}\text { Procedural Justice in } \\
\text { Performance } \\
\text { appraisal }\end{array}$ & $\begin{array}{l}\text { Organizational } \\
\text { Politics }\end{array}$ & Turnover Intentions \\
\hline
\end{tabular}

Data Analysis:

SPSS (Statistical package for social sciences) is used for data analysis.

Scales:

For measuring relationship between over variables we used.

- 3 item scale for Turnover intention from Mobley (1996).

- 12 item scale for organizational politics from Kacmar and Ferris (1991).

- 6 item scale for procedural justice in performance appraisal from Dulebohn and Ferris (1999).

\section{Analysis and interpretation:}

Below data provides the demographical idea and study of the respondents of different categories. The respondents were total 180 samples 110 respondents are male and 70 are our female respondents.

Table 1. Demographics

\begin{tabular}{|l|l|c|c|}
\hline demographics & category & $\begin{array}{l}\text { No of } \\
\text { respondents }\end{array}$ & Percentage \\
\hline \multirow{2}{*}{$\begin{array}{l}\text { Type of } \\
\text { organization }\end{array}$} & public & 180 & 180 \\
\cline { 2 - 4 } & Private & 0 & 0 \\
\hline \multirow{5}{*}{ Level of job } & Manager grade & 80 & 44.4 \\
\cline { 2 - 4 } & Non manger grade & 100 & 55.5 \\
\cline { 2 - 4 } & Total & 180 & 100 \\
\hline \multirow{5}{*}{ Gender } & Male & 110 & 61.1 \\
\cline { 2 - 4 } & Female & 70 & 38.9 \\
\cline { 2 - 4 } & Total & 70 & 38.9 \\
\hline \multirow{3}{*}{ Education } & Masters & 80 & 44.5 \\
\cline { 2 - 4 } & Graduation & 30 & 16.7 \\
\cline { 2 - 4 } & Others & 180 & 180 \\
\cline { 2 - 4 } & Total & & \\
\hline
\end{tabular}

Table 2. Correlations

\begin{tabular}{|c|c|c|c|c|}
\hline & & GENDER & AGE & EDUCATION \\
\hline GENDER & $\begin{array}{l}\text { Pearson Correlation } \\
\text { Sig. (2-tailed) } \\
\text { N }\end{array}$ & $\begin{array}{l}1 \\
180\end{array}$ & $\begin{array}{l}-.104 \\
.238 \\
180\end{array}$ & $\begin{array}{l}.047 \\
.592 \\
180\end{array}$ \\
\hline AGE & $\begin{array}{l}\text { Pearson Correlation } \\
\text { Sig. (2-tailed) } \\
\text { N }\end{array}$ & $\begin{array}{l}-.104 \\
.238 \\
180\end{array}$ & $\begin{array}{l}1 \\
180\end{array}$ & $\begin{array}{l}.289(* *) \\
.001 \\
180\end{array}$ \\
\hline EDUCATION & $\begin{array}{l}\text { Pearson Correlation } \\
\text { Sig. (2-tailed) } \\
\text { N }\end{array}$ & $\begin{array}{l}.047 \\
.592 \\
180\end{array}$ & $\begin{array}{l}.289(* *) \\
.001 \\
180\end{array}$ & $\begin{array}{l}1 \\
180\end{array}$ \\
\hline PJinPA & $\begin{array}{l}\text { Pearson Correlation } \\
\text { Sig. (2-tailed) } \\
\text { N }\end{array}$ & $\begin{array}{l}.382(* *) \\
.000 \\
180\end{array}$ & $\begin{array}{l}.191(*) \\
.030 \\
180\end{array}$ & $\begin{array}{l}.002 \\
.985 \\
180\end{array}$ \\
\hline OrgPolitics & $\begin{array}{l}\text { Pearson Correlation } \\
\text { Sig. (2-tailed) } \\
\text { N }\end{array}$ & $\begin{array}{l}.433(* *) \\
.000 \\
180\end{array}$ & $\begin{array}{l}.043 \\
.626 \\
180\end{array}$ & $\begin{array}{l}.135 \\
.126 \\
180\end{array}$ \\
\hline TI & $\begin{array}{l}\text { Pearson Correlation } \\
\text { Sig. (2-tailed) } \\
\text { N }\end{array}$ & $\begin{array}{l}.328(* *) \\
.000 \\
180\end{array}$ & $\begin{array}{l}.059 \\
.507 \\
180\end{array}$ & $\begin{array}{l}.096 \\
.275 \\
180\end{array}$ \\
\hline
\end{tabular}


** correlation is significant at the 0.01 level (2-tailed).

*correlation is significant at the 0.05 level (2-tailed).

Accept the entire hypothesis; H1, H2, H3 and H4 respectively stating that Procedural Justice in performance appraisal has a significant relationship with Turnover intention of employees. Procedural justice in performance appraisal and Turnover intention has positive coefficients of correlation as expected respectively indicating a highly significant values and strong correlation between independent variable and dependent variable. On the other hand, Organizational politics as a mediator is positively correlated with dependent and independent variable. Moreover, the interrelationship of dependent variable, independent variable and a mediator used in this study is significant and Positive.

Table.3 Regression Analysis.

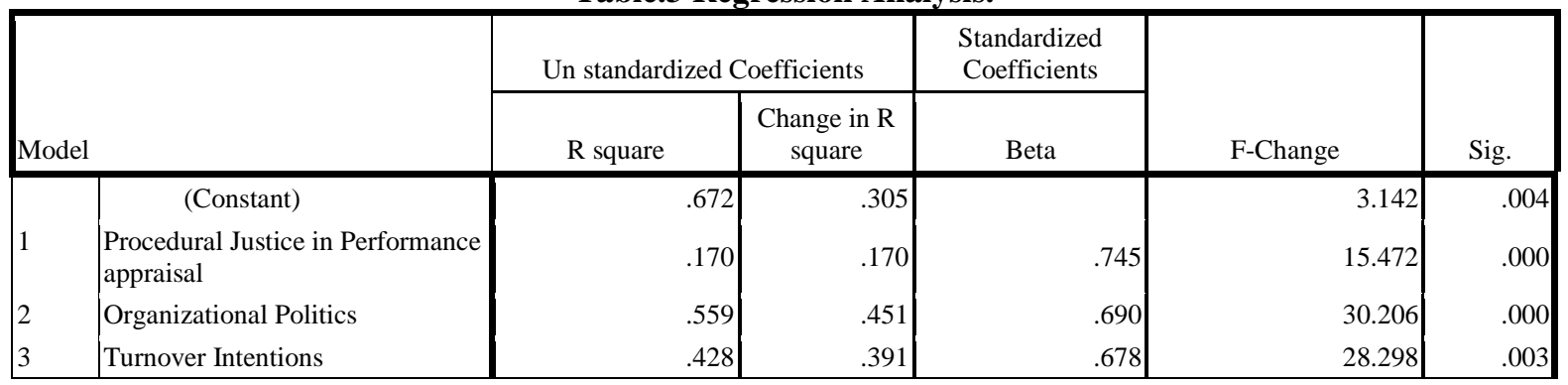

As per the model fit result shows highly significant model for our research and Cronbach's alpha shows that our variable are much reliable having the value .812 for Procedural justice in performance appraisal, .737 for Organizational Politics and .693 for Turnover Intention. Similarly that table indicates the overall model summary how much variation produce in the model and beta value is .678 shows mediation proved.

\section{Discussion}

This study was conducted to highlight the importance of the Procedural justice in performance appraisal and to access its impact on the Turnover intention of employees. And we also check the role of Organizational politics as our mediator on the Turnover intention of employees. Previous research also provides evidence of a positive impact of the organizational politics on the turnover intentions of employee. Many other researchers have also showed a very positive impact regarding the dissatisfaction of employee's $n$ terms of Organizational politics. Employee's are more dissatisfied when they observed that procedural justice is not maintained in the organizations Peoples are evaluated in terms of their links with the leader rather then the work they perform. This study provides the evidence that organizational politics in organization will increase this dissatisfaction level in terms of employees and they begin to think to switch the organization and their turnover intention is increased. Researchers also presented the other dimensions of organizational politics like employees get unsatisfied and in terms of this dissatisfaction effective outcome can not be achieved and they will decide to avoid work and absenteeism level is increased. Result taken from the respondents show a highly significant model and mediation shows the linkage with the variables. Data shows that people are unsatisfied when justice is not maintained in the organization and there dissatisfaction level will increase more when politics is also observed in the organization. This research is very helpful for the organization settings and for the leader who want to motivate and satisfy their followers and want to understand the reasons of increase in turnover intention of employees in the organization. Organizations are benefited in a way that when employees are satisfied and motivated then it shows a very positive impact in terms of outcome of the organization and similarly when they are unsatisfied organizational working is affected. Still there are some gaps left in this paper for future research which has been discussed in the future recommendation.

\section{FUTURE RESEARCH}

With reference to future research, Social exchange theory has a tendency of being too idealistic. Consider the other facilitating variables to enhance the Procedural justice in performance appraisal with other variables. It could include that the information must be gathered from different universities and organizations in order to get more precise results. We only collect our data from the public sector to check the impact of fairness in procedure in performance appraisal on the turnover intention of employees. 


\section{Bibliography:.}

[1]. Cotton, B., and G.T.Tuttle. 1996. 481-569. Palo Alto, CA: Consulting Psychologists Press. Colquitt, J. A. 2001. Journal of Applied Psychology, 86: 386-400.

[2]. Dulebohn, J.H. and Ferris, G.R. (1999),

[3]. Ferris, G. R., Russ, G. S. and Fandt, P. M. (1989). Impression Management in Organizations, Sage, Newbury Park, CA,

[4]. Ferris, G.R. et al. (1996), Stress-related implications, and outcomes', Human Relations, Vol. 49 No. 2, pp. 233-66.

[5]. Ferris, G.R., Frink, D.D., Galang, M.C., Zhou, J., Kacmar, K.M. and Howard, J.L. (1996), "Perceptions of organizational politics: prediction, stress-related implications, and outcomes”, Human Relations, Vol. 49 No. 2, pp. 233-66.

[6]. Greenberg, J. (1987) Journal of Applied Psychology, 72, 55-61.

[7]. June M Poon . (2012). AffectiveCommitment, and Turnover Intention

[8]. Kacmar, K.M. and Ferris, G.R. (1991), "Perceptions of organizational politics scale (POPS): development and construct validation", Educational and Psychological Measurement,

[9]. Price, B.G. 1999. Evolution of personnel function in India: A re-examination. Part Management and Labor Studies 19(4): 196210.

[10]. Pfe€er, J. (1981). Power in Organizations, Pittman, Boston. pp. $143 \pm 170$

[11]. Price, B.G. 1999. Evolution of personnel function in India: A re-examination. Part Management and Labor Studies 19(4): 196210.\Rawls(1921) A theory of justice.

[12]. Tse, Jeanne M., Lam, 2008. "Un-employment, Job satisfaction and Employment turnover”. Journal of Applied Psychology 72 (2): 374-81.

[13]. Walter.A2009. Ithaca, NY: Cornell University Press 